\title{
Syntactic Structure in H.P. Lovecraft's "The Picture in the House:" How the Small Choices Reveal a Horror Too Big to Know \\ Meredith Darnell*, English
}

\begin{abstract}
This paper aims to prove that H.P. Lovecraft, a celebrated twentieth-century American author of "weird fiction," terrifies the reader not with content alone but with a particular style of language. It operates on a premise that syntactic structure is a tool to analyze language in order to reveal further insights into the function of its content. It argues that the patterns in Lovecraft's style of elusive language, when parsed at a grammatical level, lay the foundations from which literary effects emerges to mold his horrifying vision of man on the precipice of madness in an incomprehensible universe. Characterized by sidestepping explication, Lovecraft's syntactic patterns in "The Picture in the House" provide ground for grammatical structure as a literary device of its own: symbols connected by these patterns heighten the story's suspense, and when woven together at the climax, they expose a secret horror still beyond our grasp, its lasting obscurity being the key demonstration of Lovecraft's inferential style.
\end{abstract}

Key Words: Coordinating Conjunction, Inversion, Left Branching Sentence, Right Branching Sentence, Syntactic Parallelism, Syntax.

In The Call of Cthulhu and other Weird Stories collection, H.P. Lovecraft is quoted explaining his motive behind writing "weird fiction," as "to achieve, momentarily, the illusion of some strange suspension or violation of the galling limitations of time, space, and natural law," and to illuminate what is "beyond the radius of our sight and analysis" (xvii). This grand intention-to briefly expose a horror beyond our sight and comprehension-develops the revelation of secret murders in a hidden cottage in "The Picture in the House." The discovery of it, however, is merely inferential. Lovecraft's style of language avoids explication, and denies the reader certain knowledge of the murderous circumstances; so, our understanding of it remains limited throughout, but that distance leads us to make conjectures about its nature. This maneuvering of language to temporarily reveal the horrible existence of it, yet still conceal an explanation for it, is a technique executed by Lovecraft at the heart of language: syntax. From the introduction of the horrible thing to come, through each suspenseful advance toward its exposure, and to its climactic reveal, grammatical structure functions as Lovecraft's tool for the preservation of its mystery. In the case of Lovecraft's style, syntax works like a literary device that constructs a framework for the reader to infer, for the moments allowed, what terrors in

\footnotetext{
* Meredith Darnell, a sprightly senior English major, loves any interaction with text she can get: she reads with a magnifying glass. Inspired by her time as Senior Fiction Editor on Unbound, $U$ of O's literary-arts journal, Meredith aspires to work in publishing. Someday she will invent a new word, visit Japan, and perhaps write a book of her own. Please send all correspondence to 22mdarnell@gmail.com.
} 
this New England cottage and in the mind of its inhabitant exist, in a way too disturbing for man to comprehend.

For the purpose of analyzing linguistic constructions as stylistic and literary devices, an approach to observing Lovecraft's style, described as "evocative prose-poetry" (xxi) must be established. In Artful Sentences: Syntax as Style Virginia Tufte writes: "But it is syntax that gives words the power to relate to each other in a sequence, to create rhythms and emphasis, to carry meaning-of whatever kind" (9). The Elements of Style confirms that connections between ideas may be realized through structure: "The likeness of form enables the reader to recognize more readily the likeness of content and function" (Strunk and White 26). Meaningsymbolic meaning especially-is inextricable from syntax. It can be further observed by experimenting with alternative arrangements seen in Tufte's comments on Steven Weinberg's writing: "Instead of writing 'the sky at night,' Weinberg turns the noun 'night' into an adjectival modifier in a noun phrase that becomes cohesive and enhances rhythm" (40). Tweaking like this lends clarity to the effect of the original composition: this is a crucial aspect of the following analysis of Lovecraft. Let it be seen, then, how syntax can parallel and create meaning in the "The Picture in the House."

Near the story's beginning, a symbolic link is made between two elements of the inexplicable horror in "The Picture in the House" simply by punctuation and a conjunction. The elements are the house which conceals the murder, and its host, an indulgent cannibal who hides his madness from the narrator. The symbolic likeness in the language performs their concealment, yet advances suspenseful intrigue. The house is described as "almost hidden now in lawless luxuriance of green and guardian shrouds of shadow; but the small-paned windows still stare shockingly, as if blinking through a lethal stupor which wards off madness by dulling the memory of unutterable things" (Lovecraft 34). The houses keep secret the horror within by remaining silent, as if enduring a voluntary coma, "dulling the memory." However, the semicolon and the conjunction "but" establish a relationship between the house and their windows: on one end we have "they are hidden," and on the other "windows stare" "blinking." The windows provide an entrance to the confined mania: what form the horror might take, unknown to us now, may be seen inside. The semicolon's pause suspends us there and the following "but" tempts us to look.

There is continuity between the appearance of the house and host: "His face, almost hidden by a long beard which grew high on the cheeks, seemed abnormally ruddy and less wrinkled than one might expect ... His blue eyes, though a trifle bloodshot, seemed inexplicably keen and burning... Of what his clothing consisted I could hardly tell, for it seemed to me no more than a mass of tatters" (Lovecraft 38). The windows "stare" much like a pair of eyes, the host's eyes. Both have an intense quality of being open, like the madness inside the house and inside the host threaten to peek at you. And like the house, the host's face and body are hidden by the overgrowth of his hair and his clothing. However, the "almost" modifies "hidden" in both passages, which tells us that some aspect of him will be made available for partial discovery just as the windows stand for a sliver of an opening to the horrors yet to be seen. This thematic connection, made outstanding due to its structural intricacies, rouses discomfort, and employs the reader in the work of collecting pieces of information by inferred connections-Lovecraft's language sidesteps clear hints to what secrets both the house and the host might have. 
This relationship between ideas of seen and unseen, and the known and the unknown keeps familiarity at bay. Lovecraft's furtive language to set the scene begins a pattern of withholding information; its nature ignites suspicion, and prepares the reader to suspend an expectation to know immediately what this horror might be. Syntactic ordering of descriptive details asserts that the upcoming horror is unknowable; we have nothing in our experience to compare it with, though we as the readers, being "searchers after horror," are familiar with other "strange, far places"-the scenes we can already imagine (Lovecraft 34).

Because we read about "strange, far places ... the catacombs of Ptolemais," "ruined Rhine castles," and "forgotten cities in Asia" before this story's setting, we understand them comparatively: "But the true epicure in the terrible, to whom a new thrill of unutterable ghastliness is the chief end and justification of existence, esteems most of all the ancient, lonely farmhouses of backwoods New England ...” (Lovecraft 34). The sharp "But" coordinates our initial imaginings of "strange, far places" with "the true epicure in the terrible" residing in the sticks of New England. "But" establishes that this scene we are heading toward is much like these "nightmare countries," (Lovecraft 34) yet this "epicure in the terrible" in a farmhouse obscured by vegetation will be relatively a worse terror above everything we might know to recall when casting about for something horrific. So, a strategically placed conjunction prepares the reader to encounter a singular and never before witnessed thing.

The scene's description continues: “... for there the dark elements of strength, solitude, grotesqueness, and ignorance combine to form the perfection of the hideous" (Lovecraft 34). The placement of the article "the" in its titles, "the true epicure in the terrible" and "the perfection of the hideous," indicate it as a singularity. Alternatively, it could read "a terrible epicure" and "a perfected hideousness." These titles typify the horror, while "the" charges it with absoluteness. "The epicure" and "the perfection" further prepare the reader to encounter a standalone horror; a single, strange happening.

But what really is "the epicure in the terrible" and "the perfection of the hideous" that we expect to encounter? Its following descriptors, the "dark elements of strength, solitude, grotesqueness, and ignorance," are curiously distant from concrete detail and a bit useless when consulted for information, much like the names given to the horror. These intangible things, like a dark element of grotesqueness, repeatedly appear as an object of a preposition. A prepositional construction draws abstract connections in these instances; the effect is to delay a concrete image of the horror. Disconnected from something knowable, it hangs in the air for now. We do not yet know which form exactly "the perfection of the hideous" will take. The structure invites us to attempt to cast the mold of what these undefined things are, which makes us curious, suspicious, and we feel a suspenseful weight in the words as a result.

Further instances of achieved concealment arise from the linguistic devices that create visual structures which reflect its content, and add to its compelling motion. The language identifying the house's exact location defines it as something hidden to then be exposed: "Most horrible of all sights are the little unpainted wooden houses remote from travelled ways" (Lovecraft 34). Attending to the placement of the subject "houses," we see that the sentence is inverted. "We approach an English sentence with certain expectations, conditioned by our long acquaintance with basic patterns. We come expecting a subject first, or soon, and next-only 
then-a predicate" (Tufte 161). Expectant of main information first, we are immediately thrust into a position of not knowing what the "sight" is. We might expect to read that "houses are the most horrible of all sights," but since we are first informed of the horrible sight, we must hold that content, along with several adjectival modifiers, "little unpainted wooden" until we are finally informed of the subject "houses." "Houses" occupies a space between a left branch and a lengthy right-branching sentence: much like the image of houses being "remote," hidden in the middle of nowhere, the actual position of "houses" is nestled away in the center of the sentence.

We follow in first person the unnamed narrator-perhaps so the reader can occupy his perspective-through his suspenseful approach to this hidden house. The suspense achieved by another type of grammatical image which is developed through prepositional phrases. They can establish directional relationships to produce a kind of cinematic movement: "The English preposition has long carried a latent verbal force ... the preposition clearly imparts a verbal force, a motion" (Tufte 118). The setting's scope finally narrows after roving around the world from Ptolemais to Asia, and continues to narrow fast. The syntax itself becomes a simulation. We follow a rather obscured route to the house that is significantly withdrawn into the woods: "upon an apparently abandoned road," "between two elms," "from the road" "up the weedy rise to the closed door." The cinematic motion follows a path, rapidly gaining distance away from civilization as we squeeze through a narrow passage, the "singular channel," through the "lawless luxuriances of green" and relentless "Nature" (Lovecraft 34-35). Like the subject "houses" is buried in the middle of the sentence, the structure here uses guiding information to illustrate a feeling of being sucked toward the ancient edifice, at once "so suggestive and secretive" (Lovecraft 35).

Upon entering and encountering the host, the appearance of a repulsive book featuring cannibalistic images of a butcher's shop and its descriptive structure heightens suspense; it makes us suspicious that the host's appreciation of human butchery is appallingly fanatical, and it is too immediate for comfort. A parallel construction winds tension: "The old man's speech grew a trifle thicker and his eyes assumed a brighter glow; but his fumbling hands, though seemingly clumsier than before, were entirely adequate to their mission" (Lovecraft 40). "Speech thicker" paired with "eyes brighter," quickens the pace of the moment just as the host's ecstatic excitement begins to build, while "seemingly clumsier" paired with "entirely adequate" draws attention to the man's familiarity with the book, which disturbs us and supports this suspicion if we recall that the "book fell open, almost of its own accord and as if from frequent consultation at this place," at the picture of butchery (Lovecraft 40). What we have been waiting for to appear is "the perfection of the hideous," some being who we are told is "the epicure in the terrible." The staring windows and the burning eyes, the host's greatly obscured location, his tender handling of the book though he is teeming with excitement over it. These details assist our imaginative crafting of the form which we have been waiting for the abstract titles to take.

Lovecraft knits the elements of the reveal together in a way that creates a momentary shock, and the implicit connections at the end ask the reader to piece the elements indicative of the revealed horror together. Through the following speech in an extinct form of Yankee dialect, the host unveils himself to the narrator as "the true epicure." Through an ecstatic, husky voice he relates to the narrator his gluttonous craving for human flesh: "I swar ter Gawd thet picter begun to make me hungry fer victuals I couldn't raise nor buy-here, set still, what's ailin' ye?-I 
didn't do nothin', only I wondered haow 'twid be ef I did-They say meat makes blood na' flesh, an' gives ye new life, so I wondered if 'twudn't make a man live longer an' longer ef 'twas more the same-But the whisperer never continued" (Lovecraft 41). The standout feature is the frequency of dashes which provide a visual clarification. They communicate pauses in his speech to account for a response to perhaps the narrator's facial reactions, and the reader's.

Especially disturbing is his response "here, set still, what's ailin' ye?” made slow and perhaps incongruously compassionate by the rhythmic commas. "But" injects a rush of suspense while the last dash interrupts momentum of the scene, and slows it to a few hot seconds. In these few seconds of the coming climactic exposure of blood on the ceiling, Lovecraft chooses "impact" and "something" to be the subjects of each clause: "It was produced by a very simple though somewhat unusual happening. As the old man whispered the words "more the same" a tiny spattering impact was heard, and something shewed on the yellowed paper of the upturned volume" (Lovecraft 42). Alternatively, it could read "we heard a tiny spattering impact" and "it shewed on the yellowed paper." The ones to do the hearing, "we" are replaced with the subject "impact," which narrows the experience to hearing the plop of the spatter. This structure adds a significant weight to this moment, which is then doubled by the following information: "I thought of the rain and of a leaky roof, but rain is not red" (Lovecraft 42). Skillfully, "rain is not red" avoids explicitly saying blood dripped onto the page, and instead the conjunction "but" establishes both a likeness between a raindrop and this liquid, and a distinction that asks the reader to assume it is in fact blood.

The final exposure again asks the reader to make a conjecture: "The old man saw it, and stopped whispering even before my expression of horror made it necessary; saw it and glanced quickly toward the floor of the room he had left an hour before" (Lovecraft 42). Here, a parallel structure communicates the focus on the sight of the red spattering: "The old man saw it...; saw it" brings our attention to the dot twice. The semicolon acts as a powerful pause between the two snapshots on the red in which we might imagine a sharp intake of breath, from both the host and the narrator, upon the surprise of its appearance. While we are absorbed by the spattering and the silence that follows its impact, Lovecraft chooses to put "glanced quickly toward the floor of the room" before "he had left an hour before" to require us to recall information we learned earlier, that the host descended from his room upstairs. It first sounds as if we are meant to look at the floor of the room the two of them currently occupy, but this asks the reader to infer that the red is blood, and that it is dripping from the host's upstairs room. This weaving of information makes the realization quite sudden, just like the surprise blood drip itself.

Even as the murder in the house and the cannibalistic host are revealed, Lovecraft's language reinforces that the horror, though we do witness it, is indeed beyond "the radius of our sight and analysis." We can merely hypothesize that this ancient Yankee seems to have survived the passage of time since the Revolutionary War by consuming humans in secret. Lovecraft maintains that distance through syntactic structures which lend only partial visuals of the revelatory blood stain. This stylistic choice must be pointed out because it greatly emphasizes that a peek at the unknown is a brief one; by the end, we still do not comprehend it all.

Prepositions, a well-established tool for Lovecraft by the end, construct the physical space of the moment we infer the host has recently murdered a man. Our vision never actually 
targets the mutilated body; we never witness the deed itself: "On the butcher's shop of the Anzique cannibals a small red spattering glistened picturesquely, lending vividness to the horror of the engraving. The old man saw it, and stopped whispering even before my expression of horror made it necessary; saw it and glanced quickly toward the floor of the room he had left an hour before. Our vision is above the picture, "On the shop," then underneath the ceiling, which we know from "toward the floor of the room." These directional relationships establish a connection between the picture's gruesome content and whatever lies above; we oscillate between the depicted butchery and the host's room now suggested to hold a bloody mess.

However, the vision is in a detached place; we are left hovering above one horror and below the other without an overt mage to grasp onto. Perhaps we imagine the host having guzzled down the blood and tenderly chewed on a still-beating heart, bloated and gleaming in the room's "air of archaism," under the light of fading candles in "the prevailing gloom." A shadowy room of purples and reds, "dusty windows," a musky smell, the body being dragged around a floor that creaks with every clunk accompanying the ax blow (Lovecraft 36). But, the point is that the gradual hints toward the house and host as living relics from a prerevolutionary time, and the realization of the cannibalism as the host's means of sustenance, still remain distant from our eye, and the details of the event stay mystifying and incomprehensible.

Because Lovecraft's linguistic techniques of withholding information, of a gradual inclusion of telling detail, and of obscuring our vision at the climactic reveal so heavily stylize "The Picture in the House," the words which Lovecraft chooses to place at the very end should be considered: "I did not shriek or move, but merely closed my eyes. A moment later came the titanic thunderbolt of thunderbolts; blasting that accursed house of unutterable secrets and bringing the oblivion that alone saved my mind" (Lovecraft 42). This last bit reinforces the reveal of something hidden by acting as a closure to follow it, emphasizing the brevity of the horror's exposure. Coordinating conjunction "but" and adverbial modifier "merely" hint that this instance of realization happened quickly, without time for the narrator to react to the "abhorrent creature," (Lovecraft 41) only a second long enough for him to close out the horrifying host in front of him. "The titanic thunderbolt of thunderbolts" is in keeping with Lovecraft's preference for absolute titles, which acts as a deus ex machina to suddenly demolish the horror, as if its exposure requires an event to render the house, its host, and the murder forever incomprehensible; we are denied an opportunity to cross its threshold again.

From the secretive language that prepared us for an unknown horror, to the gradual nods toward the house as an anomalous relic from the past and the host as a gluttonous cannibal, to the final reveal of the murder inspired by the picture, Lovecraft's favoring of implicit information invites the reader to cross into the realm of a terror too disturbing to fully realize. Skirting around explicit language, Lovecraft's subtle linguistic patterns-placement of coordinating conjunctions, slight manipulations of articles, prepositional phrases as abstract, directional and spatial connections, parallelisms, and simply punctuation-support and drive Lovecraft's intention: to plunge the reader into the unknown, to bloom through the framework.

Through Lovecraft's linguistic devices we were sent into darkness, and even as the details seemed to cohere as the story picks up momentum, we are still left without a full comprehension of the events. After all, the peek beyond our "radius of sight and analysis" is constructed from 
the interplay of syntax and content as an illusion; we never learn the complete truth behind the circumstance of this mystifying house out of time, this unthinkable disaster of a man, and his murder out of sight. Like the house attempts to "dull the memory of unutterable things" which took place inside, perhaps we as the now terrified readers should return to the limited space in which we began. As stated by the narrator, the devastation of the house "alone saved my mind;" even an inferred sight through the veil which obscures such a horror can be only momentary if we hope to return to a comprehensible place with our minds intact.

\section{ACKNOWLEDGEMENTS}

I would like to thank Carolyn Bergquist, my Art of the Sentence instructor, English advisor, and project mentor. Her enthusiasm during each Art of the Sentence session supported my interest in studying language at such a close level for the first time. I am glad to have expanded my vision of possible perspectives in which words can be observed and played with; the best advice I gleaned from the course is that one has endless options when it comes to composing thoughts on paper. Thank you for the opportunity to engage with text in such a manner-I indulge in the pleasure of a more sensitive awareness to language every day.

\section{WORKS CITED}

Lovecraft, H.P. "The Picture in the House." The Call of Cthulhu and other Weird Stories. Ed. S.T. Joshi. New York: Penguin Group, 2011. 34-42. Print.

Tufte, Virginia. Artful Sentences: Syntax as Style. Chesire: Graphics Press LLC, 2011. Print.

Strunk, William Jr. and E.B.White. The Elements of Style. Needham Heights: Allyn \& Bacon, 2000. Print. 